\title{
Formulation of Bio Degreaser Made from Palm Oil Methyl Ester Sulfonate Surfactant with Oxalic Acid Additive
}

\author{
Illah Sailah*, Erliza Hambali, Fadilla Eka Aulyana \\ IPB University, Bogor 16151, Indonesia
}

\begin{abstract}
The development of bio degreaser made from palm oil surfactant aims to substitute bio degreaser made from petroleum surfactant which is less environmentally friendly. The development was carried out by formulating palm methyl ester sulfonate (MES) surfactant with oxalic acid as metal or non-metal cleaning agent. The purpose of this study was to obtain the best concentration of oxalic acid in the bio degreaser formulation. The concentrations of oxalic acid tested were 7,8 , and $9 \%$. The best concentration of oxalic acid was determined based on the results of characteristic tests and detergency tests, namely $7 \%$ oxalic acid concentration. The resulting bio degreaser product has a pH of 1.6; viscosity $1.39 \mathrm{cp}$; specific gravity of 1.012 ; surface tension $32 \mathrm{dyne} / \mathrm{cm}$ and detergency power $84 \%$. Furthermore, the resulting bio degreaser was added with Diethanolamioda (DEA) surfactant. The purpose of adding DEA surfactant is to increase the $\mathrm{pH}$ and lower the surface tension. The formulation results showed an increase in $\mathrm{pH}$ from 1.6 to 3.2 and a decrease in surface tension from $31.97 \mathrm{dyne} / \mathrm{cm}$ to $28.70 \mathrm{dyne} /$ $\mathrm{cm}$. In addition, there was an increase in viscosity from $1.39 \mathrm{cp}$ to $1.62 \mathrm{cp}$ and specific gravity from 1.012 to 1.018 .
\end{abstract}

Key words: diethanolamide, detergency tests, environment

\section{INTRODUCTION}

The palm oil industry is one of the strategic industries in Indonesia. Indonesia's palm oil production capacity was recorded at more than 50 million tons in 2020 . Therefore, the added value needs to be increased. One alternative to increase the added value of palm oil is to process it into a bio degreaser.
Bio degreaser is needed to clean oily or greasy dirt on the surface of industrial machines, factory floors, workshop floors, and kitchens that are difficult to clean using ordinary soap. If the machine in the factory is not cleaned, the accumulation of greasy dirt can result in a decrease in engine performance which affects the production process at the factory. If the sticky greasy dirt on the factory floor, workshop or kitchen is not cleaned, over

Corresponding author:

Agroindustrial Technology Department, Faculty of Agricultural Technology,

IPB University, Bogor 16680, Indonesia.

E-mail: illahsailah@apps.ipb.ac.id. 
time a black crust will form which is unsightly and makes the floor slippery.

Currently, most of the bio degreaser used in industry to clean oily dirt made from petroleum surfactants, one of which is Linear Alkyl Sulfonate. LAS is a surfactant that is not environmentally friendly because it is toxic and not renewable (Suryani et al. 2012). Therefore, it is necessary to look for alternatives, namely surfactants made from vegetable oils.

Indonesia's potential source of vegetable oil is palm oil. Palm oil can be further processed into surfactants. Surfactants are amphiphilic compounds that have two groups in one molecule, i.e., a hydrophilic polar group and a nonpolar group that is hydrophobic. These main properties play an important role in uniting two materials that have different polarities. Therefore, surfactants are widely used as the main ingredient in cleaning products such as bath soap, shampoo, detergent, and other cleaning products (Sana \& Kailani 2017).

In the metal industry, oxalic acid is often used as metal or non-metal cleaning agent (Sunarti 2016). Therefore, in the bio degreaser formulation in this study, oxalic acid was added as a treatment factor.

\section{MATERIAL AND METHODE}

The materials used in the bio degreaser formulation were MES surfactant, distilled water (aquadest), DEA surfactant, and oxalic acid. The materials used in the detergency test were cooking oil and acetone.

The equipment used in this research were beaker glass, hot plate, magnetic stirrer, thermometer, pipette, spatula, digital scale, Schott $\mathrm{pH}$ meter, Spinning Drop Tensiometer, Brookfield DV-III Ultra Rheometer and Anton Paar DMA 4500M density meter, oven, and desiccator.

\section{Bio Degreaser}

MES surfactant was dissolved into distilled water according to the set concentrations. The homogenization process was performed for 20 minutes at a temperature of $60{ }^{\circ} \mathrm{C}$. The concentration of MES surfactant in water was $7.5 \%$. Then, oxalic acid was added at a concentration of 7,8 and $9 \%$ at a temperature of $60{ }^{\circ} \mathrm{C}$ while stirring until homogeneous.

\section{Bio Degreaser Formulation}

The bio degreaser formulation made from palm oil surfactant used was the formulation from PT. Ratu Bio Indonesia. Table 1 presented the bio degreaser formulation used in the study.

Table 1 Bio degreaser formulation made from palm oil surfactant

\begin{tabular}{lc}
\hline Material & Percentage (\%) \\
\hline MES surfactant & 7.50 \\
Aquadest & 92.50 \\
\hline
\end{tabular}

Then, 7,8 and $9 \%$ oxalic acid was added. The best formulation was added with DEA surfactant until the $\mathrm{pH}$ matched the SNI $\mathrm{pH}$. The bio degreaser formulation with oxalic acid additive is presented in Table 2.

Table 2 Design of palm oil bio degreaser formulation with oxalic acid additive

\begin{tabular}{lcrr}
\hline Material & \multicolumn{3}{c}{ Percentage $(\%)$} \\
\hline MES surfactant & 7.50 & 7.50 & 7.50 \\
Aquadest & 91.87 & 91.78 & 91.69 \\
Oxalic acid & 0.63 & 0.72 & 0.81 \\
\hline
\end{tabular}

\section{Characteristic Analysis}

The analyses included $\mathrm{pH}(\mathrm{pH}$ Meter Schott), viscosity (Brookfield Viscometer DV3T), specific gravity (Anton Paar DMA 4500M density meter), surface tension (Spinning Drop Tensiometer TX 500C), and detergency power analysis. 


\section{Experimental Design}

The data obtained were analyzed using a completely randomized design method:

$Y i j=\mu+T i+\varepsilon i j$

Note:

Yij = the value or response of the observation on the replication-j of the treatment-i

$\mu=$ general mean value

$\mathrm{Ti}=$ variance due to treatment-i

$\varepsilon i j=$ random effect on the replication-j of the treatment-i.

\section{RESULT AND DISCUSSION}

\section{PH}

$\mathrm{pH}$ is one of the quality requirements that affects the properties of the soap produced, whether it is acidic or alkaline (Khairiady 2017).

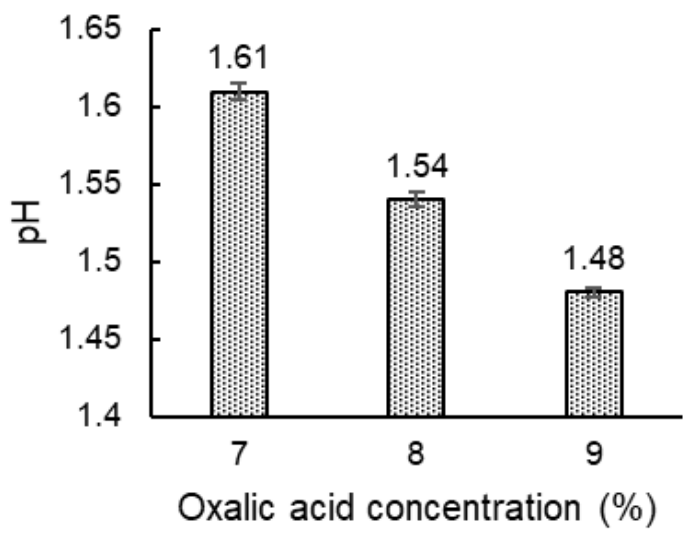

Figure 1 The effect of oxalic acid on the $\mathrm{pH}$ of bio degreaser.

The results of the ANOVA test showed that the concentration of oxalic acid affected the $\mathrm{pH}$ of the bio degreaser. Further Tukey test results showed that each treatment was significantly different.

According to SNI 4075-2:2017 regarding liquid washing detergent for cleaning materials for kitchen utensils, the $\mathrm{pH}$ quality requirements are in the range of $3-8$.
However, the $\mathrm{pH}$ values of all treatments were below the SNI quality requirements. Therefore, it is necessary to develop ways to increase the $\mathrm{pH}$ of the bio degreaser. One way to increase the $\mathrm{pH}$ of the sample is to add DEA surfactant, because DEA surfactant is one of the surfactants that has a high $\mathrm{pH}$ value.

The low $\mathrm{pH}$ value of the bio degreaser is caused by oxalic acid as one type of strong acid. Bio degreaser that is too acidic can cause corrosion on the surface of equipment or machinery made of metal and causing rust (Sinaga 2020). Based on the results of the analysis, the best treatment was a $7 \%$ oxalic acid concentration with the highest $\mathrm{pH}$ of 1.61 .

\section{Viscosity}

Viscosity is one of the parameters to determine the thickness of the bio degreaser (Muna et al. 2021). Viscosity is one of the important parameters in bio degreaser products because it can provide information on physical properties.

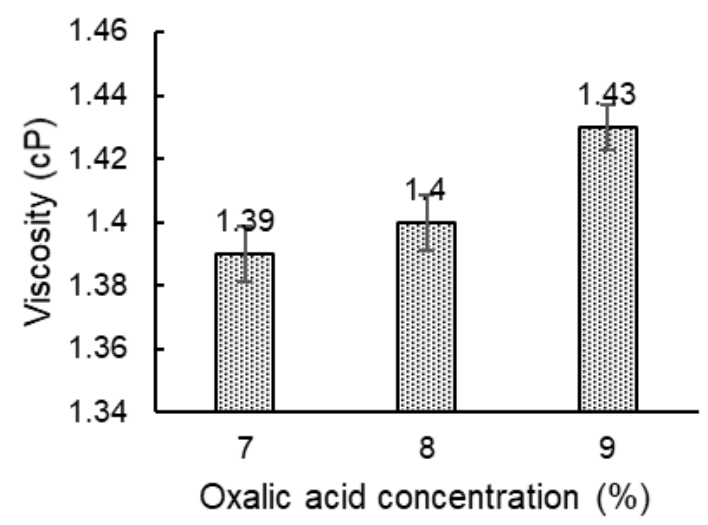

Figure 2 The effect of oxalic acid on the viscosity of bio degreaser.

The results of the ANOVA test showed that the concentration of oxalic acid affected the viscosity of the bio degreaser. Further Tukey test results showed that the treatment with $7 \%$ oxalic acid concentration was significantly different from other treatments. However, the treatment of $9 \%$ 
oxalic acid concentration was not significantly different from the $8 \%$ oxalic acid concentration treatment. Observational data showed that a higher concentration of oxalic acid results in a thicker bio degreaser. (Gandasasmita 2009).

\section{Specific Gravity}

Specific gravity is the ratio between the sample density and the density of a standard substance, such as water. Measurement of specific gravity is important to obtain information on whether a substance can be mixed with other substances (Predianto et al. 2017).

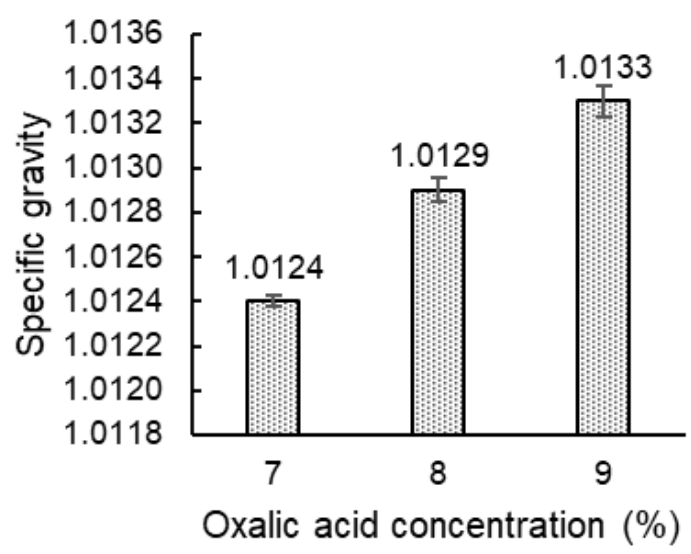

Figure 3 The effect of oxalic acid on the specific gravity of bio degreaser.

The results of the ANOVA test showed that the concentration of oxalic acid affected the specific gravity of the bio degreaser. Further Tukey test results showed that each treatment was significantly different. According to SNI, the specific gravity of soap is in the range of $1.0-1.55$. The results of the treatment showed that all the produced bio degreaser fulfilled SNI. The increase in the percentage of oxalic acid in the bio degreaser formulation showed an increasing trend. This was due to the higher density of oxalic acid than the MES surfactant solution.

\section{Surface Tension}

Surface tension is an attempt to expand a liquid surface per unit area. The surface tension of water is formed due to the attractive force between water molecules with the same strength.

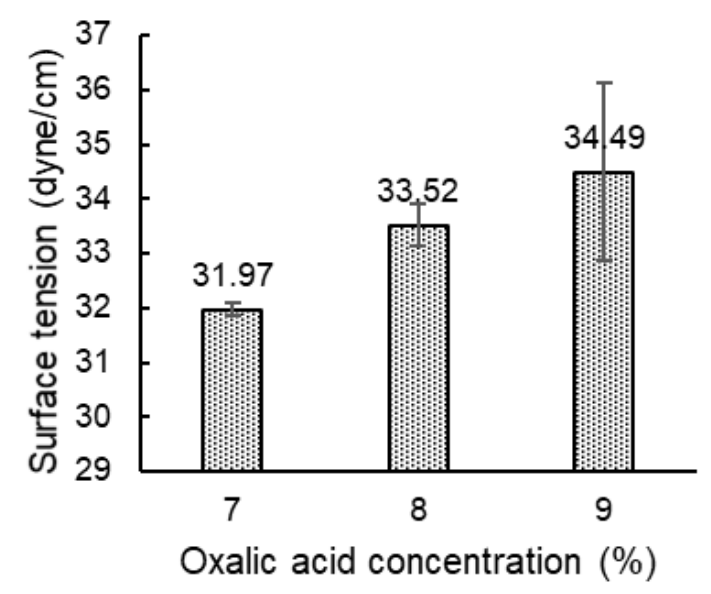

Figure 4 The effect of oxalic acid on the surface tension of bio degreaser.

The results of the ANOVA test showed that the concentration of oxalic acid affected the surface tension of the bio degreaser. The decrease in surface tension is because surfactants have polar and nonpolar groups which cause surfactants to be able to mix oil and water (Probowati et al. 2012). The smaller surface tension value results in the better cleaning power of the bio degreaser, the emulsion system is more stable, and the ability of water to wet a surface is greater. The treatment that generated the lowest surface tension was $7 \%$ oxalic acid concentration.

\section{Detergency Power}

The detergency power was analysed to investigate the effectiveness of the bio degreaser when cleaning the dirt on the surface of a material. The detergency power can be measured by rinsing method (Yuliyanti et al. 2019). 


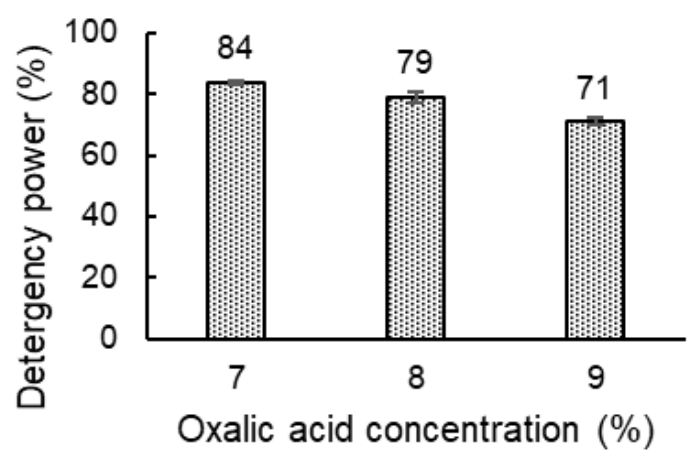

Figure 5 The effect of oxalic acid on the detergency power of biode-greaser.

The results of the ANOVA test showed that the concentration of oxalic acid affected the detergency power of the bio degreaser. Further Tukey test results showed that each treatment was significantly different.

The detergency power test was performed to investigate the effectiveness of the bio degreaser in cleaning the dirt. The higher detergency results in the better quality of the bio degreaser. As a result, the performance of the clean power of the bio degreaser is improving in removing greasy dirt.

From the results of analyses of the physical, chemical, and performance properties of the bio degreaser, the $7 \%$ of oxalic acid concentration was the best formulation of the 3 tested concentrations. However, the $\mathrm{pH}$ value in this treatment did not meet the SNI for liquid soap. Therefore, it is necessary to add other surfactants that can increase the $\mathrm{pH}$ and also function as a surface tension reducer. The added co-surfactant is preferable to the nonionic surfactant type. This is because non-ionic surfactants usually do not have a bad effect on the emulsion system that has been formed (Rachmawati 2019). It can even help lower the surface tension of cleaning products. One of the non-ionic surfactants that have a $\mathrm{pH}$ of about 10 is the diethanolamide surfactant (DEA).
The addition of DEA surfactant as a co-surfactant was applied with the main aim of increasing the $\mathrm{pH}$ and lowering the surface tension of the bio degreaser. DEA surfactant was added as much as $16.5 \mathrm{~g}$ into $100 \mathrm{~g}$ of bio degreaser product with $7 \%$ oxalic acid concentration.

The results of the analysis showed that the $\mathrm{pH}$ of the bio degreaser product was increased from 1.61 to 3.22 . The $\mathrm{pH}$ value obtained has fulfilled the SNI quality requirements for liquid soap, which is in the range of 3-8. The surface tension was decreased from 31.97 dyne/cm to 28.70 dyne/cm. The decrease in surface tension was due to non-ionic surfactants having good surface tension lowering ability (Probowati et al. 2012)

The viscosity value of the bio degreaser product was also increased from 1.39 $\mathrm{cP}$ to $161.76 \mathrm{cP}$. This was due to the characteristics of the DEA surfactant in the form of a viscous fluid. The specific gravity of the bio degreaser was also increased from 0.001 to 1.015 and still fulfilled the quality requirements according to $\mathrm{SNI}$ for liquid soap.

\section{CONCLUSION}

The best concentration of oxalic acid in the bio degreaser formulation was $7 \%$. The higher concentration of oxalic acid results in a lower $\mathrm{pH}$, the higher surface tension of the bio degreaser.

The addition of non-ionic DEA surfactant as a co-surfactant was able to increase the bio degreaser $\mathrm{pH}$ to 3.2 and decrease the surface tension to 28.70 dyne/cm. The detergency power of the bio degreaser reached $84 \%$. This means that the resulted bio degreaser can release greasy dirt as much as $84 \%$ of the amount of greasy dirt. It is necessary to perform further testing of the bio degreaser such as skin irritation, antibacterial, and shelflife testing. 


\section{REFERENCES}

[BSN] National Standards Agency. 2017. Liquid Washing Detergent - Part 2: for Kitchen Appliances. SNI 4075-2-2017. Jakarta (ID): National Standards Agency.

Arnelli. 2010. Sublation of surfactants from detergent solution and residual washing detergent solution and reuse as detergent. J Kim Sains \& Apl. 13(2):35 - 40.

Gandasasmita HD. 2009. Utilization of chitosan and carrageenan in liquid soap products [SKRIPSI]. Bogor (ID): Institut Pertanian Bogor.

Khairiady A. 2017. The formulation of dish soap with various concentrations of kaolin-bentonite as a cleanser for Najis Mughalladzah [SKRIPSI]. Jakarta (ID): UIN Syarif Hidayatullah.

Muna T, Zakaria N, Fonna L. 2021. Formulation and evaluation of patchouli essential oil liquid soap preparations (Pogostemon cablinbenth). J Sains Kesehat Darussalam. 1(1):51 - 60.

Predianto H, Momuat LI, Sangi M. 2017. Production of liquid bath soap made from VCO added with carrot extracts (Daucus carrota). Chem Prog. 10(1): $24-28$.

Probowati A, Giovanni PC, Ikhsan D. 2012. Production of surfactants from virgin coconut oil (VCO) through the amidation process with $\mathrm{NaOH}$ catalyst. J Teknol Kim Ind. 1(1):424-432.

Rachmawati A. 2019. Synthesis and characteristics of stearic acid-based nonionic surfactants through propoxylation reactions [SKRIPSI]. Jakarta (ID): Syarif Hidayatullah State Islamic University.
Sana AW, Kailani Z. 2017. Palm oil surfactant application for textile cooking-bleaching and dyeing processes. Arena Tekst. 32(1):41-50.

Sinaga AJ. 2020. Analysis of corrosion rate and hardness of 316 I stainless steel and low carbon steel in $10 \% \mathrm{NaCl}$ solution on time variations [SKRIPSI]. Medan (ID): Universitas HKBP Nommensen.

Suryani A, Syamsu K, Saputra D, Suparman K, Sulaeman I, Sukmawati Y. 2012. Acceleration Of Innovation In The Palm Oil Industry To Increase Global Competitiveness. Bogor (ID): Indonesian Palm Oil Society (MAKSI).

Yuliyanti M, Husada VMS, Fahrudi HAA, Setyowita WAE. 2019. Optimization of the quality and detergency power of liquid detergent preparations of mahogany seed extract (Swietenia mahagoni). J Kim Pend Kim. 4(2):65-76.

\section{APPENDIX}

Detergency power testing procedure (Arnelli 2010):

\section{a. Standard dirt making}

A total of $10 \mathrm{~g}$ of palm oil was suspended with acetone into a 15 gram beaker glass. The solution was put into a $250 \mathrm{~mL}$ volumetric flask and acetone was added to the mark. The flask was closed and shaken for about 5 minutes.

\section{b. Substrate making}

The substrate was made of cotton fabric. The cotton cloth is cut into pieces to a size of $10 \times 10 \mathrm{~cm}$. The cotton cloth was dried in an oven at $105^{\circ} \mathrm{C}$ for 3 hours until the cloth weight was constant. The cloth 
was then put in a desiccator for about 1 hour. The cloth was weighed and recorded as the Initial Net Fabric Weight (NFW). The fabric is called the substrate.

\section{c. Detergency power test}

The substrate was put into a $500 \mathrm{~mL}$ beaker glass containing standard dirt. Standard dirt and substrate were stirred thoroughly for 30 minutes. The substrate was removed and aerated for about 30 minutes. After the substrate was dry, the substrate was placed in an oven at a temperature of $105^{\circ} \mathrm{C}$ for 3 hours. The substrate was then placed in a desiccator for 1 hour. Then it was weighed and recorded as gross fabric weight (GFW). The percentage of sticky dirt was calculated by the following formula:

$\mathrm{PD}=[(\mathrm{GFW}-\mathrm{NFW}) / \mathrm{NFW}] \times 100 \%$

PD : Percentage of sticky dirt

GFW : Gross fabric weight

NFW : Initial net fabric weight
The substrate was then washed with bio degreaser for approximately 30 minutes and rinsed with running water. Then the substrate was aerated. The dried substrate was placed in the oven at $105^{\circ} \mathrm{C}$ for 3 hours and then was put in a desiccator for 1 hour. The dry substrate was weighed and recorded as final net fabric weight (NFW'). The percentage of dirt reduction was calculated by the following formula:

$P D^{\prime}=\left[\left(G F W-N F W^{\prime}\right) / N F W^{\prime}\right] \times 100 \%$

PD' : Percentage of dirt reduction

GFW : Gross fabric weight

NFW' : Final net fabric weight

Then from the data, the detergency power value was calculated by the following formula:

Detergency $=$ PD' $/ P D \times 100 \%$ 